\title{
Magnetic and Hydrophobic Composite Polyurethane Sponge for Oil-Water Separation
}

\author{
Peng Jiang ${ }^{1, *}$, Kun Li ${ }^{1}$, Xiquan Chen ${ }^{1}$, Ruiqi Dan ${ }^{1}$ and Yang Yu ${ }^{2, *(D)}$ \\ 1 Key Laboratory for Green Chemical Process of Ministry of Education, \\ School of Chemical Engineering \& Pharmacy, Wuhan Institute of Technology, Wuhan 430073, China; \\ likun1322871715@foxmail.com (K.L.); chenxiquan_wit@163.com (X.C.); danruiqi_9@163.com (R.D.) \\ 2 School of Civil and Environmental Engineering, University of Technology Sydney, \\ Sydney NSW 2007, Australia \\ * Correspondence: PengJiang_edu@163.com (P.J.); Yang.Yu@uts.edu.au (Y.Y.)
}

Received: 19 January 2020; Accepted: 17 February 2020; Published: 21 February 2020

\begin{abstract}
Crude oil spills from offshore oil fields will cause serious pollution to the marine ecological environment. Many 3D porous materials have been used for oil-water separation, but they cannot be widely used due to complex preparation processes and expensive preparation costs. Here, a facile and cheap approach to disperse expanded graphite (EG), stearic acid, and $\mathrm{Fe}_{3} \mathrm{O}_{4}$ magnetic nanoparticles on the skeleton surface of polyurethane (PU) sponge to prepare the magnetic and hydrophobic composite polyurethane sponge for oil-water separation. The results show that the composite PU sponge had a strong oil absorption capacity for various oils, the oil adsorption capacities has reached $32-40 \mathrm{~g} / \mathrm{g}$, and it has become more hydrophobic. The addition of $\mathrm{Fe}_{3} \mathrm{O}_{4}$ magnetic nanoparticles endowed the sponge with magnetic responsivity, and the composite PU sponge still had a strong oil adsorption capacity after several adsorbing-squeezing cycles. The magnetic and hydrophobic composite polyurethane sponge is a very promising material for practical oil adsorption and oil-water separation.
\end{abstract}

Keywords: oil-water separation; polyurethane sponge; magnetic; hydrophobic; oil adsorption capacity; reusability

\section{Introduction}

With the rapid development of the petroleum industry, more and more oilfields are exploited, including many offshore oilfields. However, problems such as oil spills can occur in the process of oil extraction, especially oil spills in offshore oil fields can pollute the marine environment [1-3]. It is especially important to recover the leaked oil from the surface of seawater. Many materials have been used to adsorb oil from water, but their efficiency and selectivity in oil/water separation are not high enough [4-9]. Changing the wetting properties of the material surface changes the selective adsorption of water-oil. A variety of oil-adsorbing and hydrophobic materials for oil-water separation have been prepared and encouraging results were obtained [10-12]. In addition, there are many 3D porous materials with hydrophobic and oil adsorption capacity that have been successfully applied to oil-water separation, but their practical applications are still limited by complex preparation methods and high raw material costs [13-17].

Polyurethane (PU) sponge is a commercially obtained low-cost 3D porous material with strong adsorption capacity and reusability. Many studies have reported the preparation of functional polyurethane sponges for oil-water separation, but the preparation cost was high and the amount of oil adsorption was insufficient [18-25]. Yu et al. [26] bonded the reduced graphene oxide (rGO) onto the surface of polyurethane (PU) sponge using (3-aminopropyl)triethoxysilane and titanium(IV (triethanolaminato)isopropoxide and found that pump oil adsorption capacities of sponges are around 
20-30 g/g. Pan et al. [27] coated the robust superhydrophobic polysiloxane layer onto the surface of 3D porous polyurethane sponges and the crude oil and bean oil adsorption capacities of sponges are around $24 \mathrm{~g} / \mathrm{g}$ and $23 \mathrm{~g} / \mathrm{g}$, respectively. From the above findings, it can be seen that the preparation process of the above-mentioned hydrophobic oil-adsorbing polyurethane sponge for oil-water separation is complicated and the preparation cost is high, and it is extremely inconvenient to recover the sponge from the surface of seawater.

Therefore, it is necessary to prepare a PU sponge with low cost, simple preparation process, and magnetic properties, which can be applied to oil-water separation. Expanded graphite (EG) is a porous worm-shaped material formed by the expansion of natural graphite flakes at high temperatures, and it is extremely inexpensive and has a strong adsorption capacity [28-32]. Stearic acid is a water-insoluble fatty acid, which has good hydrophobic properties and is inexpensive [33-36]. $\mathrm{Fe}_{3} \mathrm{O}_{4}$ magnetic nanoparticles are a kind of spinel ferrite with stable magnetic permeability and superparamagnetism, and the preparation process of $\mathrm{Fe}_{3} \mathrm{O}_{4}$ magnetic nanoparticles is simple and inexpensive [37-40]. In this work, we attempted to disperse $\mathrm{EG}$ and $\mathrm{Fe}_{3} \mathrm{O}_{4}$ magnetic nanoparticles into the polyurethane sponge, and apply a stearic acid coating on the skeleton surface of the polyurethane sponge to form a hydrophobic and magnetic sponge for oil-water separation. The EG attached to the skeleton surface of the polyurethane sponge can enhance the oil absorption ability, and the stearic acid coating on the skeleton surface can give the sponge better hydrophobicity. By adding $\mathrm{Fe}_{3} \mathrm{O}_{4}$ magnetic nanoparticles to the PU sponge as a filler, a PU sponge with magnetism can be obtained, thereby facilitating the use of a magnet to retrieve the PU sponge from the surface of seawater. The magnetism, oil absorption capacity, hydrophobicity, and reusability of the composite PU sponge were tested.

\section{Experimental}

\subsection{Materials}

Polyurethane $\left(\mathrm{C}_{10} \mathrm{H}_{8} \mathrm{~N}_{2} \mathrm{O}_{2} \cdot \mathrm{C}_{6} \mathrm{H}_{14} \mathrm{O}_{3}\right)$ n sponge (density: $\left.0.03 \mathrm{~g} / \mathrm{cm}^{-3}\right)$ was obtained from Yonjia Sponge Products Co., Ltd, Ganzhou, Jiangxi, China. Stearic acid $\left(\mathrm{CH}_{3}\left(\mathrm{CH}_{2}\right)_{16} \mathrm{COOH}, \mathrm{AR}\right)$ was provided from Tianjin Fuchen Chemical Reagents Factory, Tianjin, China. Expanded graphite was purchased from Kaiyu graphite powder Co., Ltd, Lianyungan, Jiangsu, China. Ferrous chloride $\left(\mathrm{FeCl}_{2}, \mathrm{AR}\right)$ was obtained from Beijing Hawk Science and Technology Co. Ltd, Jinan, Shandong, China. Ferric chloride $\left(\mathrm{FeCl}_{3}, \mathrm{AR}\right)$ was purchased from Shanghai Gongji Chemistry Co. Ltd, Shanghai, China. Absolute ethanol (AR) was provided from Zhengzhou Paini Technology Co., Ltd, Zhengzhou, Henan, China. Peanut oil was obtained from Shanghai Zhongxi Food Sales Co., Ltd, Shanghai, China. Lubricating oil was purchased from Luxianzi Co., Ltd, Shenzhen, Guangdong, China. Silicone oil was provided from Dongguan Tianyu Chemical Industry Co., Ltd, Dongguan, Guangdong, China. Ammonium hydroxide $\left(\mathrm{NH}_{3} \cdot \mathrm{H}_{2} \mathrm{O}, \mathrm{AR}\right)$ was obtained from INFO and Guangzhou Lixi Chemical Industry Co. Ltd, Guangzhou, Guangdong, China.

\subsection{Preparation of $\mathrm{Fe}_{3} \mathrm{O}_{4}$ Nanoparticles}

Magnetic ferroferric oxide $\left(\mathrm{Fe}_{3} \mathrm{O}_{4}\right)$ nanoparticles were prepared by chemical co-precipitation method [41,42]. The reaction principle is: $\mathrm{Fe}^{2+}+2 \mathrm{Fe}^{3+}+8 \mathrm{OH}^{-} \rightarrow \mathrm{Fe}_{3} \mathrm{O}_{4}+4 \mathrm{H}_{2} \mathrm{O}$. Fifty milliliters of distilled water was added to the three-necked round bottom flask, and then $\mathrm{FeCl}_{2}$ and $\mathrm{FeCl}_{3}$ were quickly weighed in a mole ratio of 1:2 and added to the three-necked round bottom flask. A measuring cylinder was used to measure $50 \mathrm{~mL}$ ammonia water $(25 \% \sim 28 \%)$ and added to a three-necked round bottom flask. After vacuuming, nitrogen $\left(\mathrm{N}_{2}\right)$ was introduced as a protective gas. The three-necked round bottom flask was placed on a magnetic stirrer at a temperature of $90 \mathrm{C}$ and stirred at $800 \mathrm{r} / \mathrm{min}$ to $900 \mathrm{r} / \mathrm{min}$ for $24 \mathrm{~h}$. After $24 \mathrm{~h}$, the reaction product was magnetically separated with a strong magnet and washed three times with absolute ethanol. And the reaction product was dried in a vacuum oven for $12 \mathrm{~h}$ to finally obtain magnetic $\mathrm{Fe}_{3} \mathrm{O}_{4}$ nanoparticles. 


\subsection{Preparation of Composite Sponge Samples}

Firstly, the commercial PU sponge was cut into many pieces of square shape $(2 \mathrm{~cm}$ in width and length, $1 \mathrm{~cm}$ in height) and cleaned with absolute ethanol three times, and then square sponges were put into a drying oven to dry for $2 \mathrm{~h}$ at the temperature of $80{ }^{\circ} \mathrm{C}$. Next, $0.05 \mathrm{~g}$ of magnetic $\mathrm{Fe}_{3} \mathrm{O}_{4}$ nanoparticles and $0.01 \mathrm{~g}$ expanded graphite were added into two beakers with $20 \mathrm{~mL}$ absolute ethanol and dispersed in ultrasonic cleaner for $1 \mathrm{~h}$. Then the square sponges were put into two beakers and dispersed in ultrasonic cleaner for $1 \mathrm{~h}$. The square sponges were taken from the beakers and put into a drying oven for $2 \mathrm{~h}$ at the temperature of $80^{\circ} \mathrm{C}$. Twenty milliliters of absolute ethanol was added to each of the two beakers, and then $1 \mathrm{~g}$ of stearic acid was dissolved in one of the beakers and no stearic acid was added to the other beaker. The sponges obtained from the above steps were immersed into two beakers for $2 \mathrm{~h}$, respectively. Finally, sponges were taken from the two beakers and put into a drying oven for $2 \mathrm{~h}$ at a temperature of $80^{\circ} \mathrm{C}$. The composite sponge sample 2 modified by stearic acid and the composite sponge sample 1 not modified by stearic acid were obtained. The schematic preparation of the magnetic composite sponge is illustrated in Figure 1. The specific masses of magnetic $\mathrm{Fe}_{3} \mathrm{O}_{4}$ nanoparticles, expanded graphite, and stearic acid for different sponge samples are shown in the Table 1.

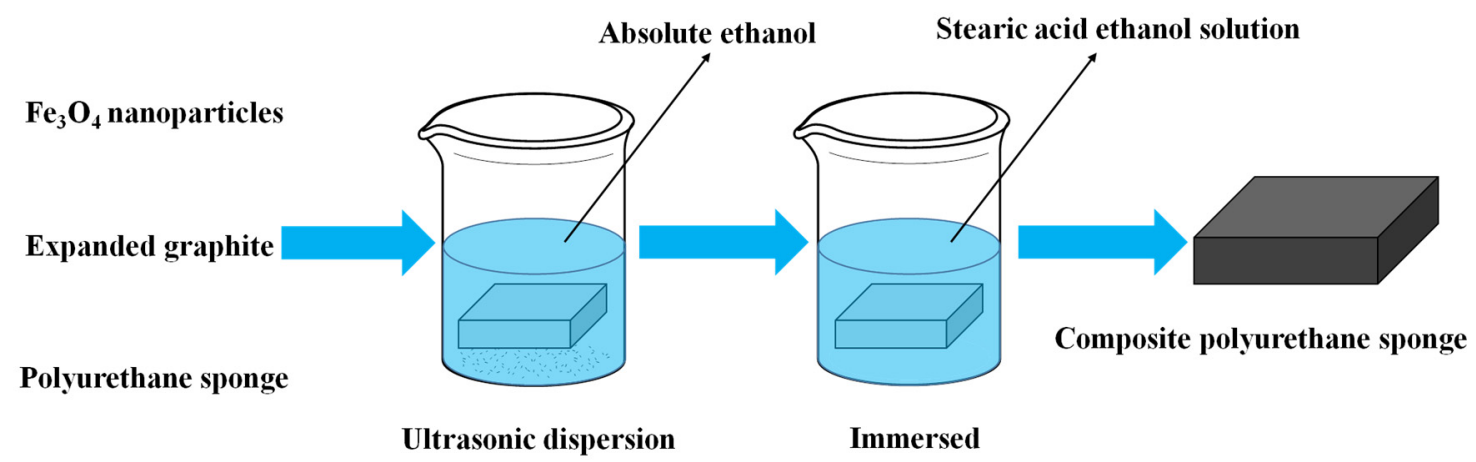

Figure 1. Schematic preparation of magnetic and hydrophobic composite polyurethane sponge.

Table 1. The specific masses of magnetic $\mathrm{Fe}_{3} \mathrm{O}_{4}$ nanoparticles, expanded graphite, and stearic acid for different sponge samples.

\begin{tabular}{cccc}
\hline Sample & $\mathrm{Fe}_{3} \mathrm{O}_{4}$ Nanoparticles (g) & Expanded Graphite (g) & Stearic Acid (g) \\
\hline 1 & 0.05 & 0.01 & 0 \\
2 & 0.05 & 0.01 & 1 \\
\hline
\end{tabular}

\subsection{Characterization}

The morphology of magnetic $\mathrm{Fe}_{3} \mathrm{O}_{4}$ nanoparticles was characterized by transmission electron microscope (TEM; F-30, FEI-Tecnai, $300 \mathrm{kV}$, Hillsboro, USA). $\mathrm{Fe}_{3} \mathrm{O}_{4}$ nanoparticle samples for TEM observations were prepared by dropping the ethanol solution of $\mathrm{Fe}_{3} \mathrm{O}_{4}$ nanoparticles samples on the copper grids and drying. The morphology of composite sponge samples with a thin layer of gold prior was evaluated by scanning electron microscope (GeminiSEM 300, Germanic Carl Zeiss Co., Ltd, Oberkochen, Germany.). The FT-IR data of magnetic $\mathrm{Fe}_{3} \mathrm{O}_{4}$ nanoparticles, expanded graphite, stearic acid and sponge samples were acquired from fourier transform Infrared Spectrometer within the wave number from 400 to $4000 \mathrm{~cm}^{-1}$ (NICOLET6700, American Thermo Fisher Co., Ltd, Waltham, USA.). The water contact angles of composite sponge samples were measured with purified water by contact angle measurement at room temperature (Theta Flex, Gothenburg, Sweden.). The weight of samples was obtained from an electronic analytical balance (HC2004, HOCHOICE Co., Ltd, Shanghai, China.). 


\subsection{Method for the Oil Adsorption Tests}

All composite sponge samples were immersed in peanut oil at room temperature. The composite sponge samples were weighed firstly $\left(\mathrm{M}_{1}\right)$, and then immersed into peanut oil until the samples adsorbed peanut oil to saturation. When the sponge was completely immersed in peanut oil and sunk to the bottom of the beaker, it was saturated. They were removed from the peanut oil and weighed $\left(\mathrm{M}_{2}\right)$. The adsorption capacity $\mathrm{Q}$ is calculated according to the following equation:

$$
Q=\frac{M_{2}-M_{1}}{M_{1}}
$$

where $\mathrm{M}_{1}$ is the weight of initial sponge and $\mathrm{M}_{2}$ is the total weight of wet sponge with peanut oil. The adsorption capacities with adsorption cycles were also tested. The pre-weighed sponge samples were then immersed in the peanut oil and allowed for saturated adsorption. Once they were removed from the peanut oil, the saturated sponge samples masses were obtained. The sponge samples were squeezed thoroughly to remove most of the adsorbed peanut oil, and the absorbing-squeezing process was repeated for six cycles successively. In the beaker, the sponge was simply squeezed with a heavy object to perform a desorption test, and the peanut oil obtained was weighed for the adsorption capacity calculation. The squeezing was performed every time in the same way and squeezing tests were repeated on five sponges of the same kind. In our experimental process, to mimic the practical industrial application, the sponge samples were tested for the reusable adsorption capacity of the composite sponge within six adsorbing-squeezing cycles under pressure, successively. All the above processes were also carried out in lubricating oil and silicone oil.

\section{Results and Discussion}

The morphologies of magnetic $\mathrm{Fe}_{3} \mathrm{O}_{4}$ nanoparticles scanned by TEM are exhibited in Figure 2. The diameter of magnetic $\mathrm{Fe}_{3} \mathrm{O}_{4}$ nanoparticles is between $10-20 \mathrm{~nm}$, and the particle size reaches the nanoscale. The magnetic $\mathrm{Fe}_{3} \mathrm{O}_{4}$ nanoparticles are spherical and dispersed. As shown in Figure 3, the magnetic $\mathrm{Fe}_{3} \mathrm{O}_{4}$ nanoparticles are firmly attracted to the glass wall by magnets, which shows that the magnetic $\mathrm{Fe}_{3} \mathrm{O}_{4}$ nanoparticles have excellent magnetism. The magnetic $\mathrm{Fe}_{3} \mathrm{O}_{4}$ nanoparticles which can be used in magnetic composite sponge were successfully prepared by chemical coprecipitation. Figure 4 compares the magnetic properties of the original sponge and the magnetic composite sponge by testing with magnets. Obviously, unlike the original PU sponge, the magnetic composite sponge can be easily attracted by magnets, indicating that the magnetic $\mathrm{Fe}_{3} \mathrm{O}_{4}$ nanoparticles are successfully filled into the original PU sponge.
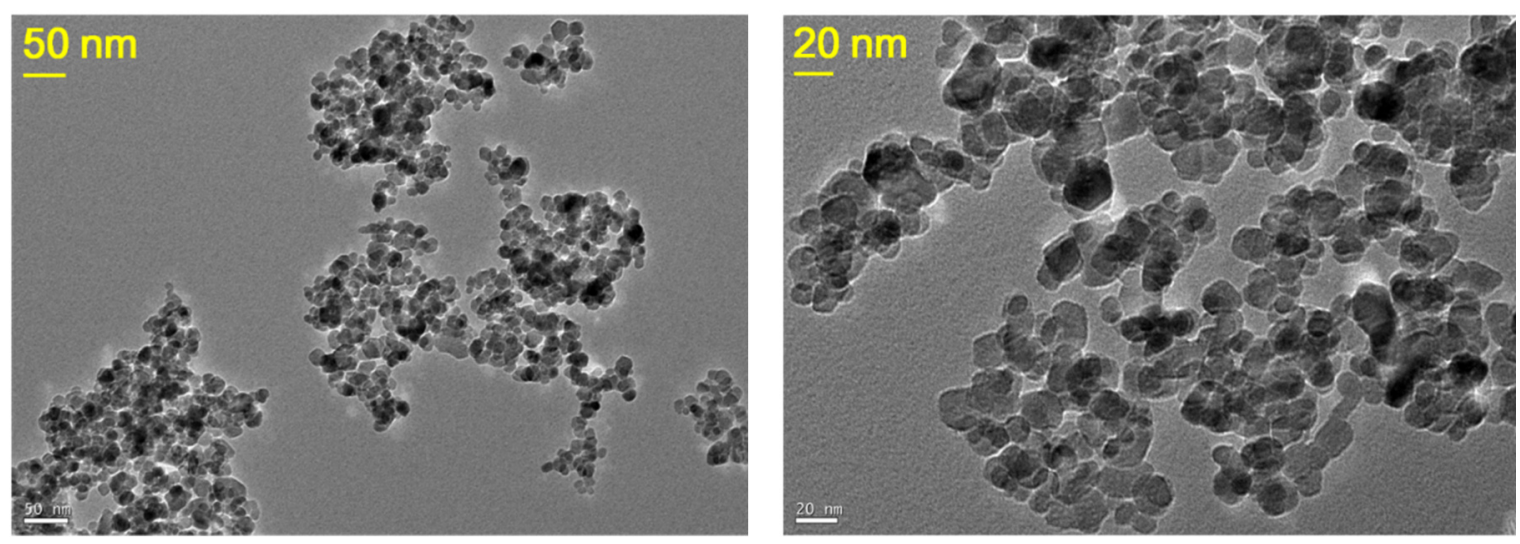

Figure 2. TEM images of magnetic $\mathrm{Fe}_{3} \mathrm{O}_{4}$ nanoparticles. 


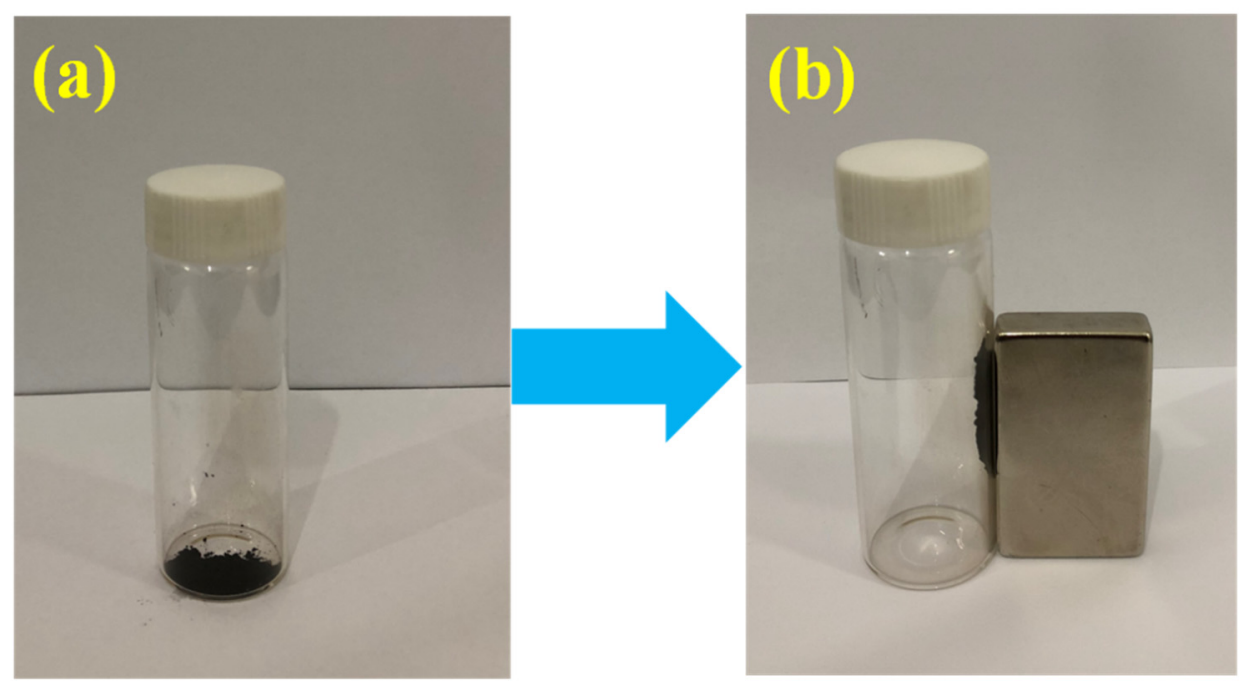

Figure 3. Digital photographs (a) $\mathrm{Fe}_{3} \mathrm{O}_{4}$ nanoparticles (b) the magnetic test by magnet for $\mathrm{Fe}_{3} \mathrm{O}_{4}$ nanoparticles.
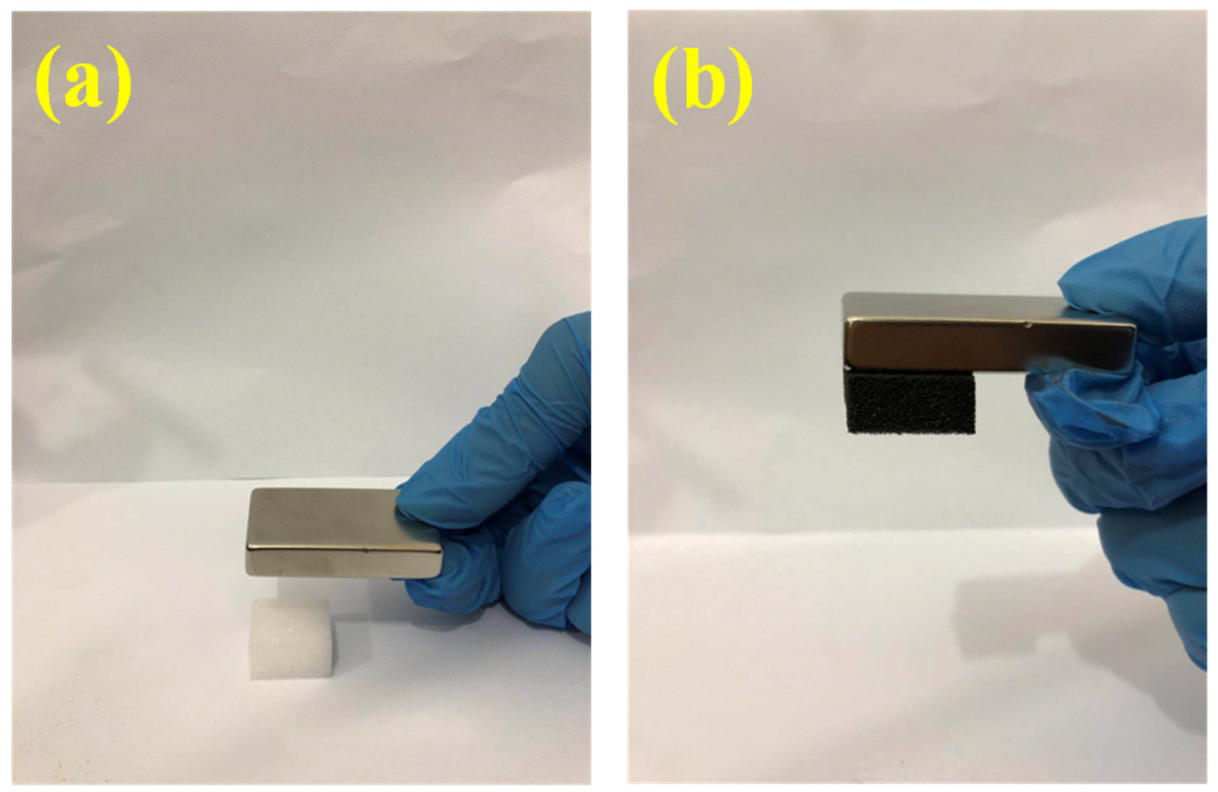

Figure 4. Digital photographs of magnetic test by magnet for (a) the original polyurethane sponge and (b) the composite sponge.

The chemical composition of the coating on the sponge was identified by FT-IR, demonstrating the existence of magnetic $\mathrm{Fe}_{3} \mathrm{O}_{4}$ nanoparticles, expanded graphite and stearic acid in composite sponge. As showed in the Figure 5, the absorption bands at $\sim 3297 \mathrm{~cm}^{-1}, \sim 2867 \mathrm{~cm}^{-1}, \sim 2275 \mathrm{~cm}^{-1}, \sim 1721 \mathrm{~cm}^{-1}$, $\sim 1106 \mathrm{~cm}^{-1}$, and $\sim 1542 \mathrm{~cm}^{-1}$ of line iv in FT-IR spectra are attributed to the characteristic peak of polyurethane sponge [43]. The $\mathrm{N}-\mathrm{H}$ peak at $3297 \mathrm{~cm}^{-1}$, the peak at $2928 \mathrm{~cm}^{-1}$ is attributed to the $\mathrm{C}-\mathrm{H}$ stretching of $-\mathrm{CH}_{3}$ and $-\mathrm{CH}_{2}$, and the peak at $2275 \mathrm{~cm}^{-1}$ is due to the asymmetric stretching of $-\mathrm{NCO}$. The peaks at $1721 \mathrm{~cm}^{-1}$ and $1106 \mathrm{~cm}^{-1}$ are associated with $\mathrm{C}=\mathrm{O}$ stretching in the amide, urea and ether groups respectively, and the peak at $1542 \mathrm{~cm}^{-1}$ is attributed to the amide II band. As for the line v, the FT-IR spectra of magnetic composite sponge, the absorption bands at $\sim 2919 \mathrm{~cm}^{-1}, \sim 2849 \mathrm{~cm}^{-1}$, $\sim 1703 \mathrm{~cm}^{-1}$, and $\sim 1466 \mathrm{~cm}^{-1}$ are due to the characteristic peak of stearic acid [44]. The peaks at $\sim 2919 \mathrm{~cm}^{-1}$ and $\sim 2849 \mathrm{~cm}^{-1}$ are due to the anti-symmetry and symmetric stretching vibration of $-\mathrm{CH}_{2}$, the peak at $\sim 1703 \mathrm{~cm}^{-1}$ is due to the stretching vibration of $\mathrm{C}=\mathrm{O}$ and the peak at $\sim 1466 \mathrm{~cm}^{-1}$ is ascribed to the scissoring vibration of $-\mathrm{CH}_{2}$. The absorption bands at $\sim 565 \mathrm{~cm}^{-1}$ and $\sim 3446 \mathrm{~cm}^{-1}$ 
are associated with the characteristic peak of magnetic $\mathrm{Fe}_{3} \mathrm{O}_{4}$ nanoparticles and expanded graphite, respectively [45-47]. The results of FT-IR spectra indicates that the expanded graphite, $\mathrm{Fe}_{3} \mathrm{O}_{4}$ magnetic nanoparticles and stearic acid were dispersed successfully into the original PU sponge and there is no new bond created on magnetic composite sponge surface.

The surface morphological evolution of sponge sample 1 and 2 were investigated by SEM. Figure 6(a1-a4) and Figure 6(b1-b4) shows the morphology of sample 1 not modified by stearic acid and sample 2 modified by stearic acid, respectively, which demonstrate sponge samples both have a three dimensional porous structure with pore sizes in the range of 100-500 $\mu \mathrm{m}$ and the surface are rough and the skeleton coated with expanded graphite at the range of 10-30 $\mu \mathrm{m}$. Obviously, the surface of sample 2 looks brighter than that of sample 1, indicating stearic acid coated at the surface skeleton of sponge sample 2 successfully. Compared with sponge sample 1, the surface of sponge sample 2 is rougher because of the coating of stearic acid.

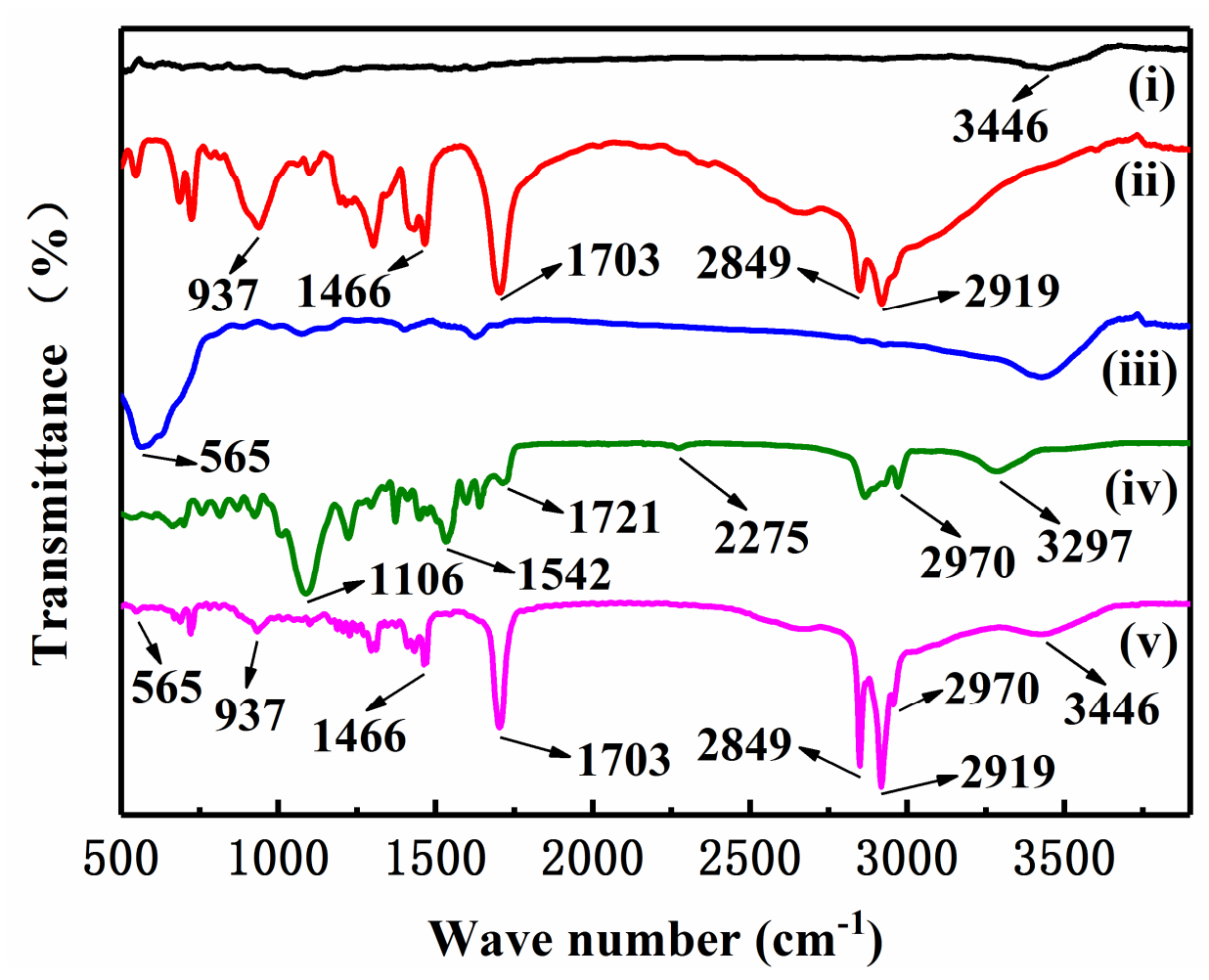

Figure 5. FT-IR spectra of (i) expanded graphite, (ii) stearic acid, (iii) $\mathrm{Fe}_{3} \mathrm{O}_{4}$ nanoparticles, (iv) original polyurethane sponge, and (v) composite sponge sample 2.

The oil-water separation experiment was performed using the sponge sample 2 and the process is shown in the Figure 7. The peanut oil was used for the experiment. The sponge was moved above the oil-water mixture and then put on the oil surface carefully. The sponge sample 2 adsorbed peanut oil completely from the oil-water mixture and suspended on the water. Finally, there was only water left in the beaker after removing the sponge. Additionally, the photographs in Figure 7a-f exhibited the process of the sponge sample 2 adsorbing a thick layer of peanut oil on the water surface. Due to its excellent mechanical flexibility, the adsorbed oils can be easily removed from the composite sponge by a simple mechanical extrusion method [48]. Due to the good hydrophobicity of stearic acid on the surface of sponge skeleton, sponges can quickly adsorb oil and block water out. 

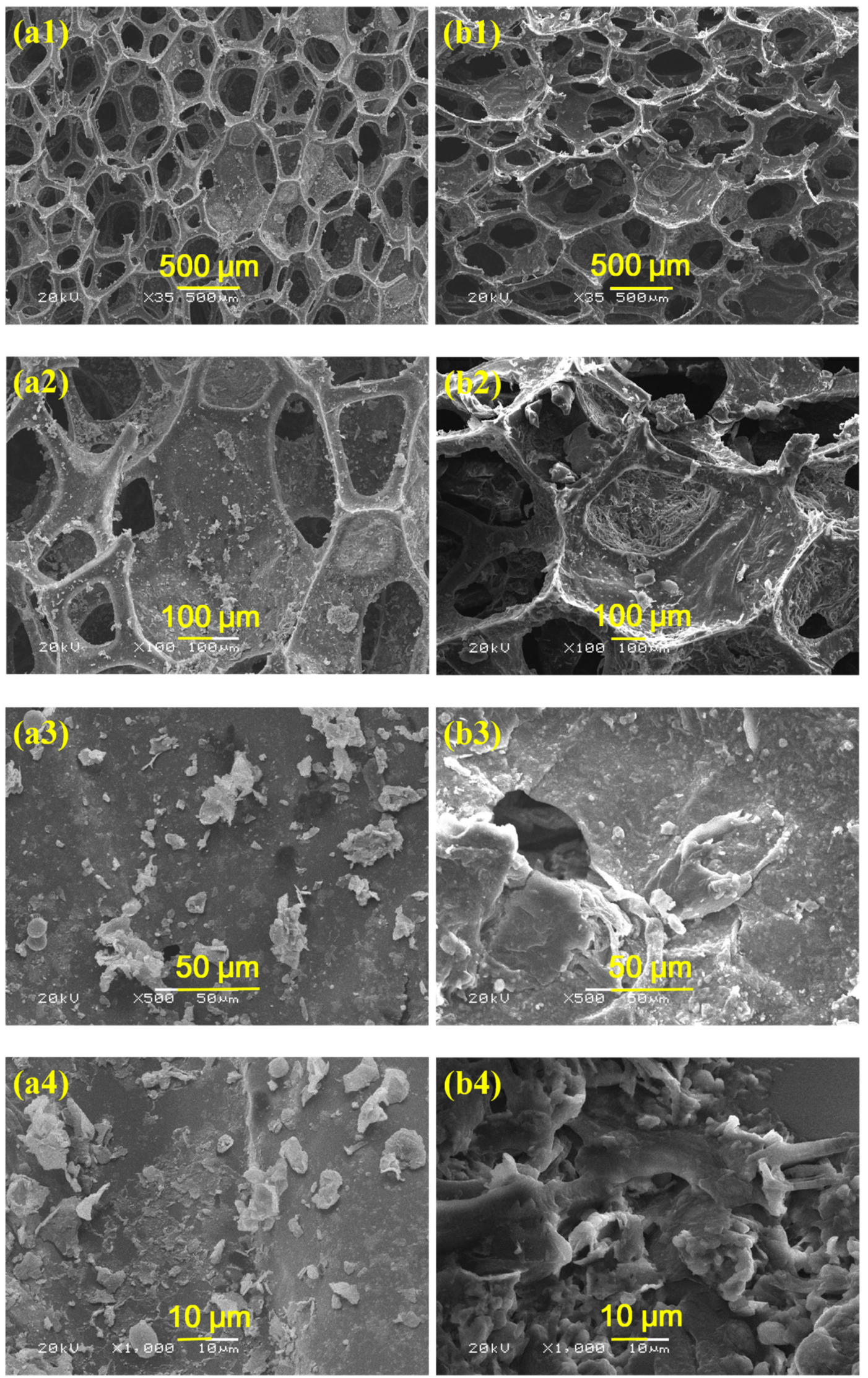

Figure 6. Morphology of composite sponge sample 1 (a1-a4) and composite sponge sample 2 (b1-b4). 
In order to explore the adsorption capacity of sponge samples, we carried out more oil adsorption experiments. For comparison, the sponge unmodified by stearic acid was also tested. Sponge sample 1 and sample 2 were tested for the oil adsorption with peanut oil, lubricating oil, and silicone oil and the results are shown in Figure 8. Obviously, the two sponge samples could adsorb a wide range of oils, and exhibits high adsorption capacities ranging from around 32-40 times of its own weight as around $32-40 \mathrm{~g} / \mathrm{g}$. Moreover, the adsorption capacities of sponge samples in this work are comparable or even better than those of the other previously reported ones, which indicates the expanded graphite coated on the sponge samples skeleton surface increased the oils adsorption capacities. The hydrophobicity of sponge samples were also tested and the results are showed in Figure 8. Compared with sponge sample 1, the water contact angle of sponge sample 2 increases to around $45^{\circ}$, which demonstrates that the hydrophobicity of the sponge enhanced after the modification of stearic acid. A stearic acid hydrophobic layer was successfully formed on the skeleton surface of sponge sample 2. From Table 2, the oil adsorption capacities of different adsorbent materials are lower than that in this work. The adsorption capacity of pure PU sponge for lubricating oil is only $28.8 \mathrm{~g} / \mathrm{g}$. Even after the modification to FGN/polyurethane sponge, the adsorption capacity of lubricating oil is only $34.2 \mathrm{~g} / \mathrm{g}$, which is still lower than that of sponge sample 1 and sample 2 in our work [49]. The times taken for the composite sponge samples to adsorb different types of oil to reach full saturation are listed in Table 3. It can been seen that the composite sponge samples adsorbed different types of oil to reach full saturation within around $20 \mathrm{~s}$.

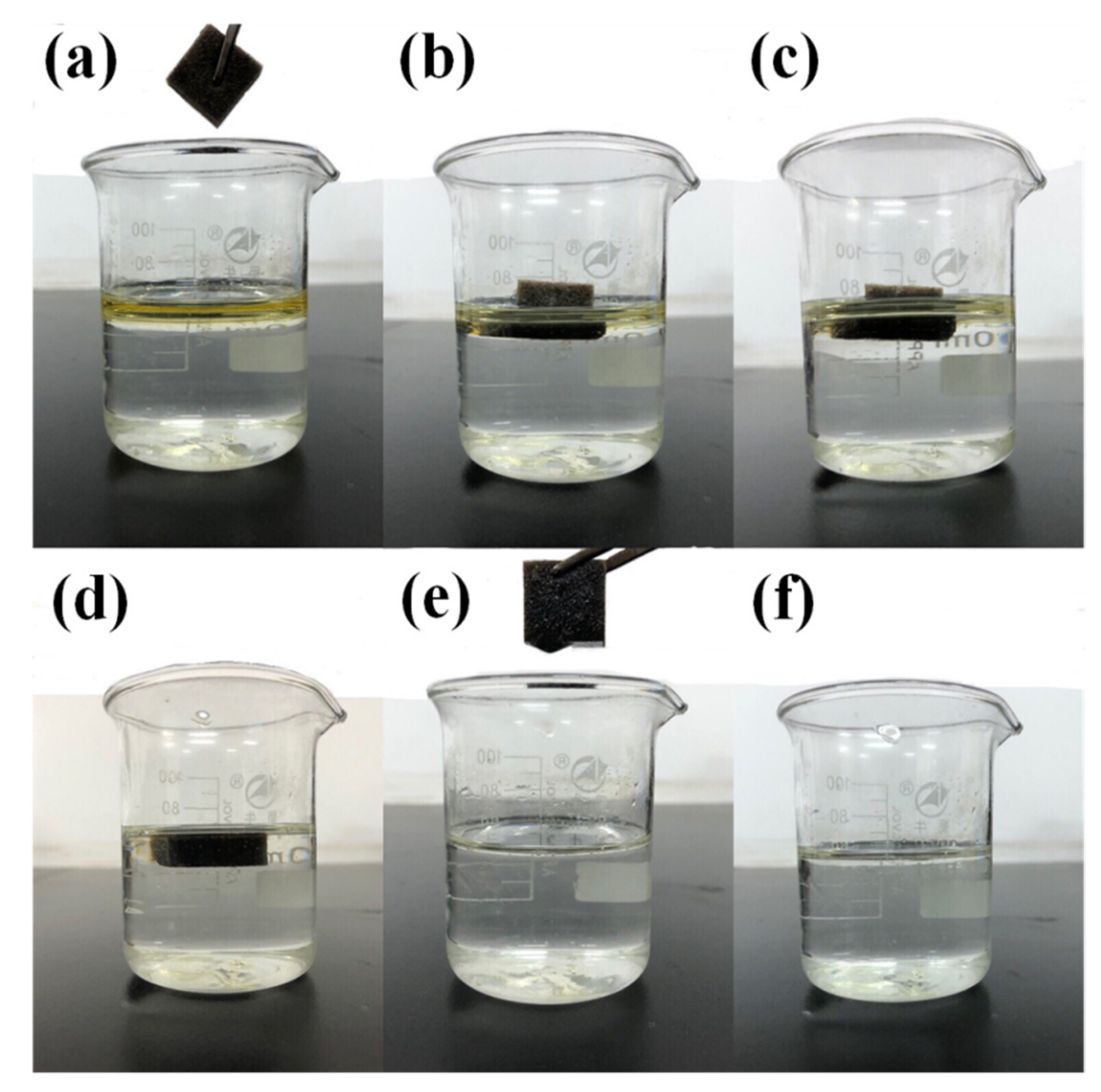

Figure 7. Digital photographs (a-f) show the oil-water separation process of composite sponge sample 2.

The reusability is a crucial index to evaluate the property of composite sponge. In practical industrial application, the sponge will be used for adsorption over several cycles successively, so the sponge will be squeezed and for the next absorbing-squeezing cycle immediately. The recyclability of sponge sample 1 and 2 for oils adsorption for six absorbing-squeezing cycles is presented in Figure 9 . 
As for the sponge sample 1, after an adsorbing-squeezing cycle, the oils adsorption capacities decreased, and with the increase of absorbing-squeezing cycles, the oils adsorption capacities turn to be stable. With the reuse of composite sponges, their adsorbent capacities slightly decreased due to the loss of adsorption capability as a result of the small amount of oil remaining on the sponge and some expanded graphite dropped off, causing the decrease of oils adsorption capacities probably [26]. In the contrast, with the increase of absorbing-squeezing cycles, the oils adsorption capacities of sponge sample 2 decrease slightly and turn to be stable. This indicates that the stearic acid hydrophobic layer formed on the skeleton surface of sponge sample 2 stopped the drop of expanded graphite in the process of adsorbing-squeezing cycles. The oil adsorption capacities of sponge sample 2 maintained stability in the process of adsorbing-squeezing cycles.

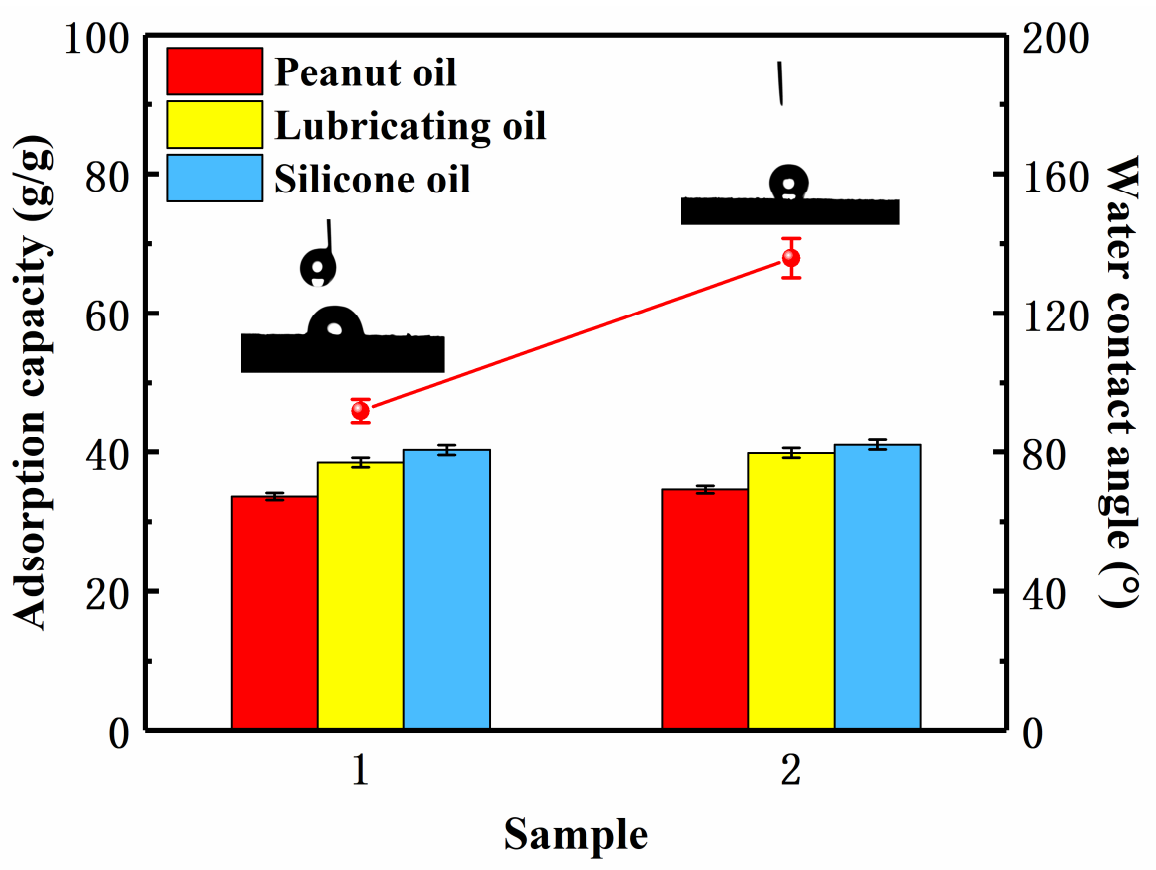

Figure 8. The adsorption capacities and water contact angles of composite sponges sample 1 and sample 2.
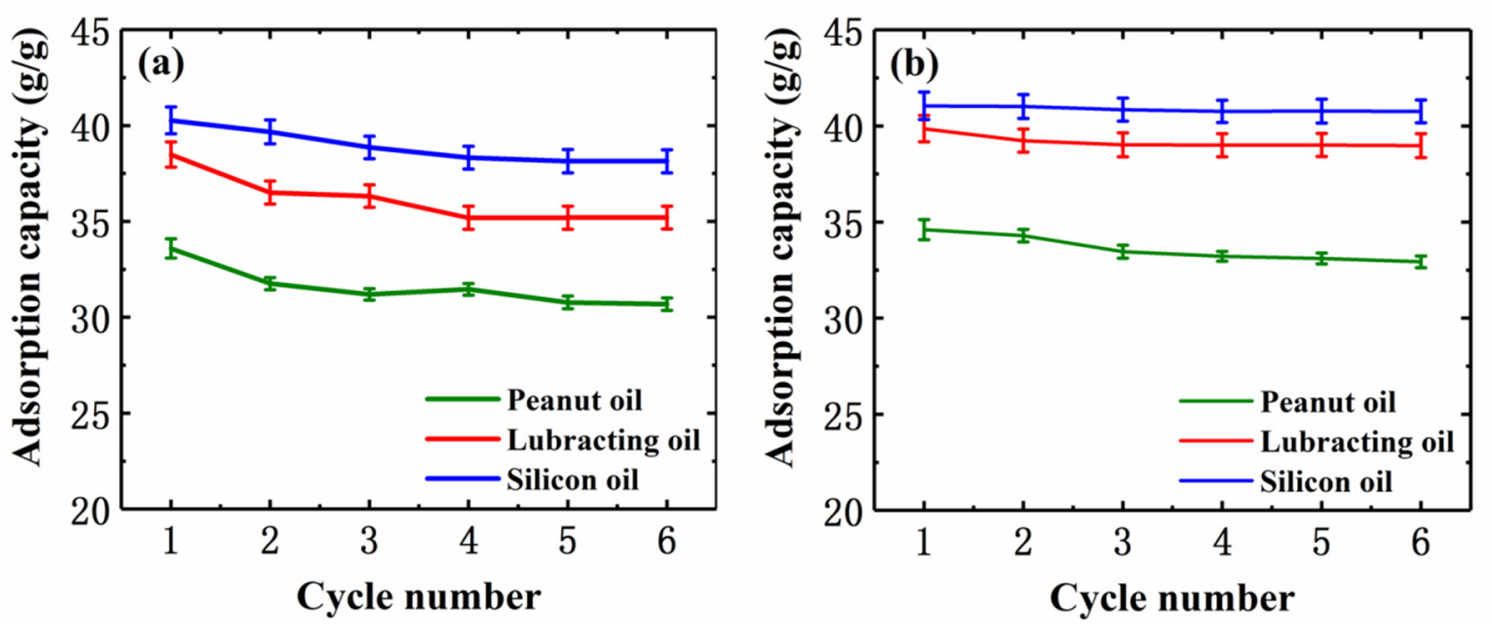

Figure 9. The adsorption capacities of composite sponge (a) sample 1 and (b) sample 2 for peanut oil, lubricating oil, and silicone oil over six cycles. 
Table 2. Oil adsorption capacity of different adsorbent materials.

\begin{tabular}{|c|c|c|c|}
\hline Adsorbent Materials & Types of Oil & Oil Adsorption Capacity & Reference \\
\hline Polyurethane sponge & Lubricating oil & $28.5 \mathrm{~g} / \mathrm{g}$ & [49] \\
\hline FGN/polyurethane sponge & Lubricating oil & $34.2 \mathrm{~g} / \mathrm{g}$ & [49] \\
\hline Superhydrophobic sponge & Lubricating oil & $24 \mathrm{~g} / \mathrm{g}$ & [27] \\
\hline $\mathrm{F}-\mathrm{SiO}_{2} /$ polyurethane sponge & Peanut oil & $15 \mathrm{~g} / \mathrm{g}$ & [50] \\
\hline $\mathrm{U}-\mathrm{SiO}_{2} /$ polyurethane sponge & Peanut oil & $28 \mathrm{~g} / \mathrm{g}$ & [50] \\
\hline PU-CNT-PDA-ODA sponge & Lubricating oil & $26 \mathrm{~g} / \mathrm{g}$ & [51] \\
\hline PU-CNT-PDA-ODA sponge & Silicone oil & $29 \mathrm{~g} / \mathrm{g}$ & [51] \\
\hline IRGO/polyurethane sponge & Pump oil & $26.5 \mathrm{~g} / \mathrm{g}$ & [43] \\
\hline IRGO/polyurethane sponge & Soybean oil & $31.2 \mathrm{~g} / \mathrm{g}$ & [43] \\
\hline IRGO/polyurethane sponge & Olive oil & $36.1 \mathrm{~g} / \mathrm{g}$ & [43] \\
\hline
\end{tabular}

Table 3. The times taken for the composite sponge samples to adsorb different types of oil to reach full saturation.

\begin{tabular}{ccc}
\hline Sample & Types of Oil & Time \\
\hline 1 & Peanut oil & $20.56 \pm 0.26$ \\
& Lubricating oil & $21.31 \pm 0.75$ \\
& Silicon oil & $21.76 \pm 0.58$ \\
2 & Peanut oil & $19.91 \pm 0.72$ \\
& Lubricating oil & $20.96 \pm 0.57$ \\
& Silicon oil & $21.38 \pm 0.63$ \\
\hline
\end{tabular}

\section{Conclusions}

In summary, a facile approach for preparing magnetic and hydrophobic composite polyurethane sponge is viable. We demonstrated that the magnetic and hydrophobic composite polyurethane sponge has an excellent performance for oil-water separation and great oil adsorption capacities ranging from around 32-40 times of its own weight. The binding of $\mathrm{Fe}_{3} \mathrm{O}_{4}$ nanoparticles, expanded graphite, and stearic acid on the skeleton surface of polyurethane sponge not only endows the sponge with magnetic responsivity and hydrophobicity, but also improves the oil adsorption capacity. The recyclability of magnetic and hydrophobic composite polyurethane sponge for oil adsorption demonstrate the sponge could still have a strong oil adsorption capacity for several adsorbing-squeezing cycles. Due to the low prices of expanded graphite and stearic acid, it is feasible to prepare a large number of magnetic and hydrophobic composite polyurethane sponges for oil-water separation in practical industrial applications.

Author Contributions: Conceptualization, P.J. and K.L.; Methodology, P.J.; Formal Analysis, P.J.; Investigation, P.J. and R.D.; Resources, K.L. and X.C.; Data Curation, P.J.; Writing-Original Draft Preparation, P.J.; Writing-Review \& Editing, P.J.; Supervision, Y.Y.; Project Administration, P.J. All authors have read and agreed to the published version of the manuscript.

Funding: This research received no external funding.

Conflicts of Interest: The authors declare no conflict of interest.

\section{References}

1. Al-Majed, A.A.; Adebayo, A.R.; Hossain, M.E. A sustainable approach to controlling oil spills. J. Environ. Manag. 2012, 113, 213-227. [CrossRef] [PubMed]

2. Wiens, J.A.; Crist, T.O.; Day, R.H.; Murphy, S.M.; Hayward, G.D. A canonical correspondence analysis of the effects of the Exxon Valdez oil spill on marine birds. Ecol. Appl. 2001, 11, 828-839. [CrossRef]

3. Dalton, T.; Jin, D. Extent and frequency of vessel oil spills in US marine protected areas. Mar. Pollut. Bull. 2010, 60, 1939-1945. [CrossRef]

4. Radetic, M.M.; Jocic, D.M.; Jovancic, P.M.; Petrovic, Z.L.; Thomas, H.F. Recycled wool-based nonwoven material as an oil sorbent. Environ. Sci. Technol. 2003, 37, 1008-1012. [CrossRef] 
5. Abdelwahab, N.A.; Shukry, N.; El-Kalyoubi, S.F. Preparation and characterization of polymer coated partially esterified sugarcane bagasse for separation of oil from seawater. Environ. Technol. 2017, 38, 1905-1914. [CrossRef] [PubMed]

6. Cardona, D.S.; Debs, K.B.; Lemos, S.G.; Vitale, G.; Nassar, N.N.; Carrilho, E.N.V.M.; Semensatto, D.; Labuto, G. A comparison study of cleanup techniques for oil spill treatment using magnetic nanomaterials. J. Environ. Manag. 2019, 242, 362-371. [CrossRef] [PubMed]

7. Ceylan, D.; Dogu, S.; Karacik, B.; Yakan, S.D.; Okay, O.S.; Okay, O. Evaluation of Butyl Rubber as Sorbent Material for the Removal of Oil and Polycyclic Aromatic Hydrocarbons from Seawater. Environ. Sci. Technol. 2009, 43, 3846-3852. [CrossRef]

8. Cojocaru, C.; Macoveanu, M.; Cretescu, I. Peat-based sorbents for the removal of oil spills from water surface: Application of artificial neural network modeling. Colloids Surf. A Physicochem. Eng. Asp. 2011, 384, 675-684. [CrossRef]

9. Yang, Y.; Tong, Z.; Ngai, T.; Wang, C. Nitrogen-Rich and Fire-Resistant Carbon Aerogels for the Removal of Oil Contaminants from Water. Acs Appl. Mater. Interfaces 2014, 6, 6351-6360. [CrossRef]

10. Gao, H.; Sun, P.; Zhang, Y.; Zeng, X.; Wang, D.; Zhang, Y.; Wang, W.; Wu, J. A two-step hydrophobic fabrication of melamine sponge for oil absorption and oil/water separation. Surf. Coat. Technol. 2018, 339, 147-154. [CrossRef]

11. Zhang, T.; Li, Z.; Lu, Y.; Liu, Y.; Yang, D.; Li, Q.; Qiu, F. Recent progress and future prospects of oil-absorbing materials. Chin. J. Chem. Eng. 2019, 27, 1282-1295. [CrossRef]

12. Zhu, J.; Liu, B.; Li, L.; Zeng, Z.; Zhao, W.; Wang, G.; Guan, X. Simple and Green Fabrication of a Superhydrophobic Surface by One-Step Immersion for Continuous Oil/Water Separation. J. Phys. Chem. A 2016, 120, 5617-5623. [CrossRef] [PubMed]

13. Shi, L.; Chen, K.; Du, R.; Bachmatiuk, A.; Ruemmeli, M.H.; Xie, K.; Huang, Y.; Zhang, Y.; Liu, Z. Scalable Seashell-Based Chemical Vapor Deposition Growth of Three-Dimensional Graphene Foams for Oil-Water Separation. J. Am. Chem. Soc. 2016, 138, 6360-6363. [CrossRef] [PubMed]

14. Liang, W.; Guo, Z. Stable superhydrophobic and superoleophilic soft porous materials for oil/water separation. Rsc Adv. 2013, 3, 16469-16474. [CrossRef]

15. Halake, K.; Bae, S.; Lee, J.; Cho, Y.; Jo, H.; Heo, J.; Park, K.; Kim, H.; Ju, H.; Kim, Y.; et al. Strategies for Fabrication of Hydrophobic Porous Materials Based on Polydimethylsiloxane for Oil-Water Separation. Macromol. Res. 2019, 27, 109-114. [CrossRef]

16. Zhang, J.; Ji, K.; Chen, J.; Ding, Y.; Dai, Z. A three-dimensional porous metal foam with selective-wettability for oil-water separation. J. Mater. Sci. 2015, 50, 5371-5377. [CrossRef]

17. Zhang, W.; Liu, N.; Cao, Y.; Lin, X.; Liu, Y.; Feng, L. Superwetting Porous Materials for Wastewater Treatment: From Immiscible Oil/Water Mixture to Emulsion Separation. Adv. Mater. Interfaces 2017, 4, 1600029. [CrossRef]

18. Zhao, P.; Wang, L.; Ren, R.; Han, L.; Bi, F.; Zhang, Z.; Han, K.; Gu, W. Facile fabrication of asphaltene-derived graphene-polyurethane sponges for efficient and selective oil-water separation. J. Dispers. Sci. Technol. 2018, 39, 977-981. [CrossRef]

19. Chen, X.-Q.; Zhang, B.; Xie, L.; Wang, F. MWCNTs polyurethane sponges with enhanced super-hydrophobicity for selective oil-water separation. Surf. Eng. 2020, 1-9. [CrossRef]

20. Zhang, L.; Xu, L.; Sun, Y.; Yang, N. Robust and Durable Superhydrophobic Polyurethane Sponge for Oil/Water Separation. Ind. Eng. Chem. Res. 2016, 55, 11260-11268. [CrossRef]

21. Cao, N.; Guo, J.; Boukherroub, R.; Shao, Q.; Zang, X.; Li, J.; Lin, X.; Ju, H.; Liu, E.; Zhou, C.; et al. Robust superhydrophobic polyurethane sponge functionalized with perfluorinated graphene oxide for efficient immiscible oil/water mixture, stable emulsion separation and crude oil dehydration. Sci. China Technol. Sci. 2019, 62, 1585-1595. [CrossRef]

22. Li, M.; Yin, X.; Li, J. Robust superhydrophobic/superoleophilic sponge for efficient removal of oils from corrosive aqueous solutions. J. Adhes. Sci. Technol. 2019, 33, 1426-1437. [CrossRef]

23. Liu, C.; Fang, Y.; Miao, X.; Pei, Y.; Yan, Y.; Xiao, W.; Wu, L. Facile fabrication of superhydrophobic polyurethane sponge towards oil water separation with exceptional flame-retardant performance. Sep. Purif. Technol. 2019, 229, 115801. [CrossRef] 
24. Yu, T.; Halouane, F.; Mathias, D.; Barras, A.; Wang, Z.; Lv, A.; Lu, S.; Xu, W.; Meziane, D.; Tiercelin, N.; et al. Preparation of magnetic, superhydrophobic/superoleophilic polyurethane sponge: Separation of oil/water mixture and demulsification. Chem. Eng. J. 2020, 384, 123339. [CrossRef]

25. Zhang, J.; Liu, X.; Chen, F.; Liu, J.; Chen, Y.; Zhang, F.; Guan, N. An environmentally friendly and cost-effective method to fabricate superhydrophobic PU sponge for oil/water separation. J. Dispers. Sci. Technol. 2019, 1-9. [CrossRef]

26. Tjandra, R.; Lui, G.; Veilleux, A.; Broughton, J.; Chiu, G.; Yu, A. Introduction of an Enhanced Binding of Reduced Graphene Oxide to Polyurethane Sponge for Oil Absorption. Ind. Eng. Chem. Res. 2015, 54, 3657-3663. [CrossRef]

27. Zhu, Q.; Chu, Y.; Wang, Z.; Chen, N.; Lin, L.; Liu, F.; Pan, Q. Robust superhydrophobic polyurethane sponge as a highly reusable oil-absorption material. J. Mater. Chem. A 2013, 1, 5386-5393. [CrossRef]

28. Chang, Y.; Wang, B.; Luo, H.; Zhi, L. Adsorption of Methylene Blue onto Secondary Expanded Graphite. Adv. Build. Mater. 2011, 168, 2571-2574. [CrossRef]

29. Tan, S.-C.; Shi, P.-H.; Su, R.-J.; Zhu, M.-C. Removal of methylene blue from aqueous solution by powdered expanded graphite: Adsorption isotherms and thermodynamics. Adv. Res. Eng. Mater. Energy Manag. Control 2012, 424, 1313-1317. [CrossRef]

30. Zhao, M.; Liu, P. Adsorption of methylene blue from aqueous solutions by modified expanded graphite powder. Desalination 2009, 249, 331-336. [CrossRef]

31. Vedenyapina, M.D.; Borisova, D.A.; Simakova, A.P.; Proshina, L.P.; Vedenyapin, A.A. Adsorption of diclofenac sodium from aqueous solutions on expanded graphite. Solid Fuel Chem. 2013, 47, 59-63. [CrossRef]

32. Vedenyapina, M.D.; Vedenyapin, A.A. Dynamic adsorption of drug preparations from aqueous solutions on thermally expanded graphite. Solid Fuel Chem. 2015, 49, 41-44. [CrossRef]

33. Emken, E.A. Metabolism of dietary stearic acid relative to other fatty acids in human subjects. Am. J. Clin. Nutr. 1994, 60, 1023S-1028S. [CrossRef] [PubMed]

34. Grundy, S.M. Influence of stearic acid on cholesterol metabolism relative to other long-chain fatty acids. Am. J. Clin. Nutr. 1994, 60, 986S-990S. [CrossRef]

35. Livesey, G. The absorption of stearic acid from triacylglycerols: An inquiry and analysis. Nutr. Res. Rev. 2000, 13, 185-214. [CrossRef]

36. Premphet, K.; Horanont, P. Influence of stearic acid treatment of filler particles on the structure and properties of ternary-phase polypropylene composites. J. Appl. Polym. Sci. 1999, 74, 3445-3454. [CrossRef]

37. Kim, M.I.; Shim, J.; Li, T.; Lee, J.; Park, H.G. Fabrication of Nanoporous Nanocomposites Entrapping $\mathrm{Fe}_{3} \mathrm{O}_{4}$ Magnetic Nanoparticles and Oxidases for Colorimetric Biosensing. Chem. Eur. J. 2011, 17, 10700-10707. [CrossRef]

38. Wei, $\mathrm{H}$.; Wang, E. $\mathrm{Fe}_{3} \mathrm{O}_{4}$ magnetic nanoparticles as peroxidase mimetics and their applications in $\mathrm{H}_{2} \mathrm{O}_{2}$ and glucose detection. Anal. Chem. 2008, 80, 2250-2254. [CrossRef]

39. Martin, M.; Salazar, P.; Villalonga, R.; Campuzano, S.; Manuel Pingarron, J.; Luis Gonzalez-Mora, J. Preparation of core-shell Fe3O4@poly(dopamine) magnetic nanoparticles for biosensor construction. J. Mater. Chem. B 2014, 2, 739-746. [CrossRef]

40. Wang, N.; Zhu, L.; Wang, D.; Wang, M.; Lin, Z.; Tang, H. Sono-assisted preparation of highly-efficient peroxidase-like $\mathrm{Fe}_{3} \mathrm{O}_{4}$ magnetic nanoparticles for catalytic removal of organic pollutants with $\mathrm{H}_{2} \mathrm{O}_{2}$. Ultrason. Sonochem. 2010, 17, 526-533. [CrossRef]

41. Shen, W.; Sun, A.; Zhai, F.; Wang, J.; Xu, W.; Zhang, Q.; Volinsky, A.A. $\mathrm{Fe}_{3} \mathrm{O}_{4}$ magnetic nanoparticles synthesis from tailings by ultrasonic chemical co-precipitation. Mater. Lett. 2011, 65, 1882-1884.

42. Kamyar, S.; Mansor, A.; Khalantari, K.; Khandanlou, R. Synthesis of talc/Fe3O4 magnetic nanocomposites using chemical co-precipitation method. Int. J. Nanomed. 2013, 8, 1817.

43. Hao, J.; Wang, Z.; Xiao, C.; Zhao, J.; Chen, L. In situ reduced graphene oxide-based polyurethane sponge hollow tube for continuous oil removal from water surface. Environ. Sci. Pollut. Res. 2018, 25, 4837-4845. [CrossRef] [PubMed]

44. Huang, H.; Tian, M.; Yang, J.; Li, H.; Liang, W.; Zhang, L.; Li, X. Stearic acid surface modifying Mg(OH)2: Mechanism and its effect on properties of ethylene vinyl acetate $/ \mathrm{Mg}(\mathrm{OH}) 2$ composites. J. Appl. Polym. Sci. 2008, 107, 3325-3331. [CrossRef]

45. Sun, J.; Zhou, S.; Hou, P.; Yang, Y.; Li, M. Synthesis and characterization of biocompatible Fe3O4 nanoparticles. J. Biomed. Mater. Res. Part A 2007, 80, 333-341. [CrossRef] 
46. Xu, C.; Wang, H.; Yang, W.; Ma, L.; Lin, A. Expanded Graphite Modified by CTAB-KBr/H3PO4 for Highly Efficient Adsorption of Dyes. J. Polym. Environ. 2018, 26, 1206-1217. [CrossRef]

47. Yang, M.; Zhao, Y.H.; Zhang, Y.C.; Li, D.X. Preparation of Modified Expanded Graphite by KOH. Adv. Mater. Res. 2011, 347, 800-803. [CrossRef]

48. Beshkar, F.; Khojasteh, H.; Salavati-Niasari, M. Recyclable magnetic superhydrophobic straw soot sponge for highly efficient oil/water separation. J. Colloid Interface Sci. 2017, 497, 57-65. [CrossRef]

49. Zhou, S.; Hao, G.; Zhou, X.; Jiang, W.; Wang, T.; Zhang, N.; Yu, L. One-pot Synthesis of Robust Superhydrophobic, Functionalized Graphene/Polyurethane Sponge for Effective Continuous Oil-water Separation. Chem. Eng. J. 2016, 302, 155-162. [CrossRef]

50. Lin, B.; Chen, J.; Li, Z.-T.; He, F.-A.; Li, D.-H. Superhydrophobic modification of polyurethane sponge for the oil-water separation. Surf. Coat. Technol. 2019, 359, 216-226. [CrossRef]

51. Wang, H.; Wang, E.; Liu, Z.; Gao, D.; Yuan, R.; Sun, L.; Zhu, Y. A novel carbon nanotubes reinforced superhydrophobic and superoleophilic polyurethane sponge for selective oil-water separation through a chemical fabrication. J. Mater. Chem. A 2015, 3, 266-273. [CrossRef]

(C) 2020 by the authors. Licensee MDPI, Basel, Switzerland. This article is an open access article distributed under the terms and conditions of the Creative Commons Attribution (CC BY) license (http://creativecommons.org/licenses/by/4.0/). 